\title{
Strengthening The Skill of Creativity and Innovation in Pre-Primary and Primary School Education
}

\author{
Zahra Soltani ${ }^{1}$, Zohreh Sadat Shamshirgaran ${ }^{2}$ \\ ${ }^{1}$ An employee of Technical and Vocational University, Employed at the Girls' School of Mashhad, MA \\ in Educational Management. Zsoltani584@gmail.com \\ ${ }^{2}$ An employee of Technical and Vocational University, an Officer at the Girls' School of Mashhad, PhD \\ in Farsi Language and Literature. shamshirgaran@live.com
}

\begin{tabular}{|c|c|}
\hline ARTICLE INFO & ABSTRACT \\
\hline $\begin{array}{l}\text { Keywords: } \\
\text { Creativity } \\
\text { Innovation } \\
\text { Pre-Primary School } \\
\text { Education } \\
\text { Growth } \\
\text { Imagination } \\
\text { Creative Visualization } \\
\text { Creative Barriers }\end{array}$ & $\begin{array}{l}\text { In the present age, students must improve their critical and creative } \\
\text { thinking skills in order to make the right decision and solve complex } \\
\text { society problems to deal with the tremendous transformations of the } \\
\text { third millennium. They should increase the research and problem } \\
\text { solving skills and the search spirit. Obviously, in order to achieve } \\
\text { these goals, there is a heavy responsibility on education centers, } \\
\text { especially education. These centers, on the one hand, undertake the } \\
\text { task of teaching knowledge and equipping students with the } \\
\text { information needed, and on the other hand, they have to provide a } \\
\text { context to help the development and growth of creativity and } \\
\text { innovation and the correct use of this talent and ability. Creativity is } \\
\text { the use of mental abilities to create a new thought or concept, the } \\
\text { process of creating new thoughts and converting those thoughts into } \\
\text { action and useful applications is called innovation. After expressing } \\
\text { the importance and necessity of developing children's creativity, this } \\
\text { paper investigates the history of the subject, the concept of creativity } \\
\text { and imagination from birth to six year-olds, the effect of game in } \\
\text { developing creativity for pre-primary and primary school education, } \\
\text { the characteristics of creativity in children, creative teaching } \\
\text { methods, important principles in developing creativity in pre-primary } \\
\text { and primary school education and ... In the end, by the mention of the } \\
\text { factors preventing creativity and initiative in the students, } \\
\text { suggestions and practical solutions for the use of parents, instructors } \\
\text { and agents have been raised. Hope to be grower of creative, } \\
\text { innovative, faithful, and very dynamic and capable children. }\end{array}$ \\
\hline
\end{tabular}

\section{problem statement}

The study of objectives of education in the world shows that the most important needs of every society is the education of those who think logically by relying on their will and reason, and, instead of dependence and use of the economic and cultural achievements of others, they themselves generate knowledge, technology and the right culture for life in the knowledge age. Therefore, in the era of increasing information and communication, the issue that most of all attracts the attention of scholars and psychologists is how to grow creativity in children, which is considered as a great human need in all aspects of future life.

* Corresponding author E-mail address: Zsoltani584@ gmail.com 
The research has shown that all the blessings and skills in children and adolescents have been forgotten due to some factors and obstacles. Therefore, in this article, we are looking for the status of creativity in children's growth and providing solutions for developing creativity in pre-primary and primary school education.

\section{The necessity and importance of the issue}

All children born have potential God-given abilities. One of these abilities is the spirit of show-off that emerges from the second year of childhood, and by this spirit, inventions, innovations and scientific advances arise. If this ability was not possible, the industrial civilization of humanity did not soar so much, we were obliged to educate a child to transform the stagnation, uniformity, into pure scanning, and by creative thinking explore stereotype forms of thinking and make a new design. The necessity of this evolution is a dynamic teaching system that requires a collective determination based on the committed hard work and sustainability and creativity. Therefore, in order to reach a creative, innovative society, we must know and apply the methods of creativity development in our children and students.

\section{Historical background of issue}

Desire to be creative throughout history and in all human societies can be seen. From prehistoric paintings in caves, we find that humans have left signs from the earliest times using the materials they have had. Troton believes that we are born with a need to understand beliefs, thoughts and feelings of others, and because of this need, the symbols of our culture, such as visual and exhibitive arts have emerged. We all have had rich experiences under the influence of the beauty of visual and exhibitive arts. Perhaps the reaction to the beauty of a painting, or a piece of music, or perhaps the myths that man has created, illustrates these rich experiences. We, humans, need to test our creativity and imagination; we need to express our thoughts, feelings and influences. We all are consumers of thoughts and artifacts that are the result of creative thinking, for example, the clothes we wear and the technology we use, we are the makers who rely on their creativity and imagination. Society always needs creative people, those who can find creative solutions and combine previous irrelevant ideas and skills with their imagination (Yasaiy, 2001: 20-19).

\section{The concept of creativity}

Creativity is a subjective process that its result is creating thoughts at the same time new and valuable. Creativity in human type is a "general" talent such as intelligence and memory and contrary to public view in humanity is not divided between innovators and non-innovators. There are also some degrees here, everyone is more or less creative (Basis, 2000: 55-53).

- Creativity is an exponential thing; in other words, all students have the potential of creativity. - Creativity is the development of awareness and the ability to absorb and benefit from all the blessings of life.

-Fantasy thought and ingenious thinking stimulate the power of creativity.

-Creativity is curiosity, the tendency to know and experience a lot of things, so it should be paid attention to the curiosity of the students."

\section{Development of creativity and imagination from birth to six year-old}

Children have access to extensive experiences in which they can develop their creativity and imagination. Imagination is related to the growth, the ability to imagine in children are 
interconnected and overlapped with all aspects of growth by becoming older to facilitate the development of imagination and creativity.

1. Cognitive development: Many of the theories of cognitive development have been taken from Piaget. His emphasis is that children understand the world through their experience. Piaget introduced the concept of the stages of growth and the changes in the mental construct of children axis.

2. Perceptual development: The development of creativity and imagination is also part of the perceptual development of children. We perceive the world through our senses, as the sense of vision, hearing and touch of children grows, their ability to perceive and understand the world increases.

3. Physical development: Children explore the world using their physical abilities and access their favorite objects. Children begin their exploration with daily things and dominate them. How can objects and materials be used? Can they be thrown, beat them, for what can be used? As the ability of children to sit, buy, and walk increases, they see the world from a new angle and their vision grows from the world.

4. Language development: Language, imagination and creativity all require the ability to represent the experience in a symbolic way, whether it is a word used against an object. The skill of listening and paying attention to detail, which is part of the imaginative and creative representations, is also important in terms of growth and literacy and language as well as the use of language develops by children, they can better share their thoughts and beliefs with others. This issue increases their imaginative game.

5. Social and emotional development: As children's social and emotional awareness and skills develop, they can join others in expressing their creativity and imagination. For example, the skills of co-operation and discipline that are essential for being part of a group grows in them. Creative and imaginative experiences, in turn, give children the opportunity to express themselves, which also contributes to their emotional and social development (Yasaiy, 2001: 87).

\section{Features of creative people}

Turnes (1998), in responding to the question of the role of personality traits in creativity, said that personality can both make creativity easier and prevent it. Features such as readiness to risk, curiosity and searching, independence of thought, perseverance and persistence, courage, independence of the vote, self-initiation, initiative, questioning about the mysterious situations and getting involved with difficult issues are, including easy features of creativity (Gominiyan, 2003). There are many personality traits that prevent creativity. Gilford considers the following features of this category: domination, negativity, resistance, fear, reproach, critique of others, compromise, submission to power and shyness.

\section{Features of creativity in children}

Creativity in children, when they discover a relationship for the first time that they have not previously discovered, Isaeburs Yalongo (1993) suggests these ways in defining creativity in early childhood. Children are creative if:

* Explore and test.

* Using your language and game, make your world meaningful.

* Focus on a task for a long time. 
* Order disturbance and do a new work by the old and familiar phenomenon.

* Learn something new by repeating (Yasaiy, 2001: 42).

The results of Turnes (1998) research on the relationship between intelligence and creativity show that the average intelligence score of creative students is between 97 and 126, and as a result, there is no significant difference in academic achievement among students with intelligence and creativity (Geminiyan citing from Seif , 2003).

1. Creative students are more interested in cultural activities than sports and social activities. Creative girls tend to be more in line with their father. They are readers of books and magazines. 2. Creative students offer a variety of clever solutions for issues. They act in their feedback and attitudes without bias, and prefer to operate in an open and unrestricted environment.

3. Creative students in group activities often play a leading role, and they go to their friends to consult rather than parents.

4. They have extraordinary and positive memory capacities and keeping various events.

5. They are ready to experience various activities and affairs.

6- Socially they have good behaviors.

7. In terms of expression, they are clear and comfortable.

8. They are active, curious and searcher and questioner.

9. There have independent and logical thoughts.

10. They have divergent thinking and do not think about things like others.

11. They are resistant, darey, criticizable and tireless.

12. They are spontaneous, honest and simple.

Having strong imagination, great and terrifying dreams are one of the main characteristics of creative students. Some of them are called disorder and turbulent. They threat the teacher by asking strange questions. Creative students tend to risk a lot, which Nixon (1962) considers this feature the distinction aspect of gifted and creative children.

\section{Creative teaching methods}

The world in which we live is changing rapidly, and the speed of this change has never been so rapid. We do not know what our children will face in adulthood, but we know that they must be creative and imaginative in order to be able to deal with these issues. An instructor should use creative displays, engaging entertainments as poet and students' opinions in techniques of his teaching methods in order to make students to adulthood,

* Cope with an unexpected thing.

* Extend their existing knowledge to new situations.

* Combine the previous irrelevant information.

* Examine new concepts.

* Cope with successive changes.

* Revaluate values and way of looking.

* Correct and guide their world

* Have flexible thinking.

* Play with concepts and materials.

* Sympathize with others.

* Work with different people in different ways.

* Make risk.

* Be the originator.

* Respond to challenges and strong imagination. 
Unfortunately, we often devalue the creative and imaginative ways of thinking that encourages these features (Yasaiy, 2001: 21).

People who are weak in the ability to diagnose issues are also weak in creating and studying different ways. In a study on the characteristics of mathematical instructors, an interesting confirmation was found on this conclusion. Every month, these instructors were asked to do three things.

1. Describe the most successful lesson of their month and mention the reasons for failure.

2. Describe the most unsuccessful lesson of their month and mention the reasons for the failure.

3. Identify an idea or concept that they have taught during the month, explain how this idea was taught, and provide all the ways that they knew for reaching the idea, and mention all the new ways that they could measure.

An optional sample of 100 records was selected among several thousands of monthly reports. These reports were divided into two groups. One of the issues those who identified problems in their teaching methods and the other those who did not have problems in their teaching performance and attributed their failure to something that was not related to their performance, then, the two groups were compared in terms of the number of different ways that they knew to teach their concept and the number of new ways that they have measured to teach the concept. The results were completely clear. Teachers who found a problem in their teaching performance were twice of those who did not identify a problem measured different ways.

In this way, it's important to avoid the many ways that easily come into your mind. (Turnes, 1996: 53-52).

Major principles in developing creativity in pre-primary and primary school education As our goal is to develop creativity and innovation in children, we must focus on three major principles:

A. Provide facilities and equipment

B. Creating motivation and movement in children

C. Unconditional support and encouragement by parents and instructors

Parents and instructors can develop the curiosity and creativity in their children according to the following points

* Selection - Children who have more possibility to select act and think more creative. So let's not limit them and always provide conditions that they have the right options to select.

* The presence of various motivations and stimuli in environment-full stimulating environment always provokes children and fosters their reasoning and creativity. These stimulants do not need to be very complicated and expensive. Parents and instructors can make the environment dynamic with simple facilities such as beans, plastic containers in various sizes, flower sculpture, and the like.

* Creating opportunity to play for children- playing is thought of child. The stories require a container called "play" to foster their power and creativity, and it is vital to provide this context for fostering children's thinking and creativity.

* Having autonomy in the certain context - Parents and instructors can let them to decide on their own affairs by encouraging them to independently think and act. Children, who are always under the supervision and care of their parents and do not have opportunity for independent thought and practice, have less creativity. 
Encouraging children to exchange ideas - Children can be encouraged to discuss and exchange opinions with their friends and relatives to solve their problems and issues and slowly learn that the use of their own thinking and others can lead to the selection of better solutions.

\section{The relationship of creativity and play}

There is a lot of relationship and overlap between the creative process and play. Play and creativity have common features. In fact, play is often part of the creativity process.

An attitude and process-mental readiness status-Ability to cope with uncertainty-Ability to explore in new concepts-Divergent thinking, i.e. the ability to look at a problem in different ways-noncoercion-the opportunity to choose-create and recreate.

Fantasy and creativity are deeply rooted in the play. Play enhances the flexibility and problem solving skills needed for creativity. Artists often say they play with materials to discover new, creative ingredients.

\section{The impact of play in developing creative for pre-primary and primary school education}

Play is the necessities of a child's life and has a significant impact on the mental and physical development of the child. Children often spend part of their time for playing; they find their strengths and weaknesses through it. Their goal is to play, to have fun, to entertain, to spend time, to know the world and to escape from sadness and turmoil. Play is a natural device for expressing emotions (Kazemi, Angeji and Türkman, 1999). By Adler's expression, playing is not timeconsuming; it is occupation of a profession that provokes the skill and prosperity of social talents (Mahjour, 2001).

The kind of human creation is such that he is born questioner and the pinnacle of his question arises in childhood. In this regard, Sandras says: "Children who make imaginary play during the future years of their life will have creative thinking and will be more capable in solving problems. Albert Einstein writes in his memoirs: "The theory of relativity could not have formed in my adulthood life, since man in adulthood doesn't have opportunity to think space and time. These are the things that I thought to them when I was a child (Mirza Aghaei , 2002).

Children's play equipment should stimulate their curiosity, they should be safe, prepared with a right price, and child has them in such a way that he doesn't lose his sense of ownership. Children need toys that can move them; change, and handle, toys which have psychological roles to the children be able to have an active role to them, not the toys that are much automated and complete, and don't leave anything for child. Automatic toys do not have interesting content because the child doesn't act and try intellectually in playing with them and he is passive, spectator, and lacking initiative in front of them (Motahari, 2002).

\section{Strategies of creativity development \\ How can develop creativity in students and children?}

1. Respect the students' questions and encourage them to find answers.

2. Encourage their comments with their creativity and provide the context for the emergence of these views.

3. Value the students' ideas and demonstrate that their beliefs are valuable.

4. Sometimes without raising the threat of evaluation, letting them free in class to carry out targeted activities.

5. You should not force them following the experts. 
6. In each field, you should create the skill and understanding required. Otherwise, it is not possible for a student to become a scientist, target or creative person with chance.

7. It should respect the students' unusual beliefs because those whose creativity are provoked understand the relationships and concepts that others may not be aware of them.

8. Students' answers to questions should be directed to new questions. When answering each question, the teacher must put the student in a new puzzle so that his mind consciously and unconsciously to be exploring.

9. Completing shapes and imperfections will develop the creativity in students, such as completing an incomplete story or predicting an unfinished event.

10. 10. You should provide opportunities for innovative learning and appreciate these types of learning.

11. Students should see and manipulate objects.

12. Ask questions that begin with how and why.

13. It is necessary for students to have leisure time activities to work freely.

14. Encourage children to look deeply into the natural phenomena surrounding them. We should educate children not to be reluctant about the issues around them. They should try to solve problems and check their mistakes. They should foster desire to know and think what kind of things and equipment they will need in the future.

15. Encourage children to think about newer and more varied solutions to problems and issues.

16. Teaching to children using various and diverse and tangible methods.

17. Honoring the abilities and talents of children, though negligible, to create curiosity and exploration spirit in children, encourage them to raise their own new ideas and views, and do not expect the same performance from children. You can dedicate a corner of the child's room to an exhibition of hand-made and research.

18. The presentation of simple puzzles causes the happiness and entertainment of children and stimulates them to search for the answer of the riddle and puzzle. Finding the relationship between mathematical chain numbers, verbal questions and memory exercises, finding answers to puzzles and games that can be effective in fostering creativity in children.

19. Studying and reading various books, reading various books will foster creative mind.

20. Support the creative and innovative ideas of the kids emotionally and spiritually. Parents and child instructors should try to provide relax, secure, trustworthy environment. Never mock idea of children, don't compare him with others because it makes children to be disappointed and removes their creativity. It is not necessary that the inventive hand work of children to be "beautiful", "perfect", "without fault", it should be more on the process of doing the work than the result.

21. Allowing for a safe nest, creative children try to innovate by allocating a place for keeping equipment and the preparation of simple and diverse equipment. Due to "endeavor and error," they repeat their experiments repeatedly and, without feeling the least tired and desperate, they are seeking to succeed and achieve their goal, we should not disrupt their means or prevent them from doing so.

\section{The importance of representation in children}

Children need to represent their experiences, feelings and beliefs so that they can share them with others. When we represent, we do something that object or symbol appear instead of another thing. For example, using imagination, the child pretends that the baby puppet is real, or by drawing a 
picture shows his experience of going to the zoo. Mathews (1994) emphasizes the importance of achieving the child's ability. For example, if they pretend that a wood is not wood and can be used, for example, as comb, it's easy to understand that the sign "cat" on a paper page that does not look like a cat but can represent a cat. Children show their experiences in different forms. They may Design an image - Explain an experience in the form of words - Practically represent the role of playing a situation- Create a model with cubes - Show emotional state with dance and movements - Paint a picture - Make a piece of music.

Children explore using their representations, solve problems, and think about new concepts and create them. Different forms of representation enable them to see different problems in different ways and find new insights. The ability and possibility of representing children is a matter of domination. And as a result, they get a better idea. Mc Kler (1957) distinguishes between reproduction and creativity. When we are reproducing, we use only one source of information, and the result is predictable. When we are creative, we get information from different sources to combine together to create a coherent whole (Yasaiy, 2001: 29-26).

\section{Leisure and creativity}

Studies indicate that leisure time has been always a good context for creativity and innovation. In leisure time, a human being can think freely and use divergent thinking in solving problems in his cognitive domain. Therefore, the use of hours and leisure time is an important factor in preventing the undesirable effects of time pressure such as anxiety and excitement and will play a significant role in providing psychological health and crystallizing thoughts (Baharestan, 2006).

\section{Other models of creative solving of issues}

As a teaching method, a sales strategy, or a way to discipline children is limited. Applying and mastering only on one creative solution model is a deterrent to us in creating different ways. In the techniques of creative problem solving, such as the technique of thoughtful rainfall (Osborne), the technique of why, the technique of what, if ..., synthetic technique, ... methods have been developed to create a variety of systematic and disciplined methods. A review of the strategies for the above and other forms of the process of creative solving of issues have several psychological properties. All of them have strategies to facilitate the process of warming up and starting, all of which are methods for asking questions that causes problem solvers to measure information in a variety of ways, and from systematic and structural ways to focus on different aspects of a problematic reality (Turnes, 2000).

\section{The inhibitors of creativity and innovation}

One of the reasons for the fact that as children grow older, their creativity decreases, is that they fall into the trap of habitual living. Whereas, if we try to break the habit chain and present different ideas to find the answers to the problems, so that we do not just use the past experiences to solve new problems, we have somehow abled to foster creative thinking in the children with thinking method. Some of the factors that reduce the intellectual creativity of children include:

1. Reward: When a person does not expect to receive a reward for what he has done, he will use more creativity and enjoy his work.

2. Internal motivation against external motivation: When we use external motivations such as money, gifts, etc., as reward in fact, we eliminate creativity and innovation in children and adolescents. Artists believe that when they only for satisfaction and their 
intrinsic pleasure create a work, they work more productive than when they receive salary for their work.

3. 3. Waiting for the evaluation of innovation and artwork: When a person knows beforehand his work is evaluated and classified, his creativity and innovation are reduced in his work and activities.

4. Pressures from friends and relatives: Research shows that stress and psychological pressures on children and adolescents by friends and peers prevent them from developing their creative talents.

5. Extreme supervision and care: If the child is constantly under care and supervision, the process of creativity decreases in him and, fearing criticizing, he fails to work (Salahshur, 2004).

\section{Harmful factors in creativity}

The harmful factors in creativity have raised concerns for the education system at the community level and it is a serious threat to the development of the talents and abilities of children and adolescents. The harmful factors of creativity can be divided into two categories:

1- Individual factors (psychological)

2. External environmental factors

It can be referred to the following cases briefly:

Parents 'expectations, disregarding the children's essential needs, excessive purchasing of toys, parents' opposition to some games, the most important of which are: a) being dirty of children's clothing; b) misinterpretation of parents from squalor; cool environment of family, away from ambiguous situations, parenting intolerance, blaming, discriminating, coercion, compliance and obedience to conventional methods and restrictive rules, lack of awareness of parents from spontaneous learning, convincing children, suppressing children's imagination, high emphasis on exam score

\section{Barriers of creativity in the family environment}

* Overemphasis of parents on child's intelligence and memory

* Creating competition among children, competition between children usually occurs when:

A. There is a kind of assessment and ranking by parents.

B- There is a reward or prize.

These competitions turn into militancy among children and make them unable to use their real talents and abilities

* Establishing restrictive rules at home

* Parents' lack of familiarity with the real concept of creativity

* Frequent criticism of child behaviors

* Not paying attention to the childhood fantasies

* Lack of familiarity of the child's inner interest

* Impose the role of an adult to a child

This issue also eliminates many of the creative talents of childhood periods (Soleimani, 2003).

\section{Barriers of creativity in the school environment}

1- High emphasis on student score as a good criterion

2- Traditional and teacher-centered teaching methods

3. The teacher's lack of knowledge to creativity 
4. Lack of minimum facilities for students' creative activities

5. Objectives and content of textbooks

6- Not paying attention to students' individual differences

7. Not accepting new ideas

8- Giving much homework to students

9. Mocking due to the wrong opinion or idea

\section{Various solutions to encourage creativity in children with practical and easy solutions}

1. Creative questions: Questions with different answers lead to divergent creativity and thinking. We must ask the children open questions, a question that has many answers, and each of them can be correct. Like: If we put this table out, what we can do with them.

2. Creative solving problem: Children can learn how to decide on their differences. We must ask them to explain their problems, to think about the solution, choose one and act, then discuss about its success with the teacher or the family.

3. Creativity pattern: Creativity is teachable more than to be learned. It should be shown to the child that we do not escape the simple tasks such as pottery and the test of a new thing, making songs and simple jokes; the child enjoys simple work and learns creativity.

4. Saying I do not know: Finding a response with the help of each other can be a pleasure. The answer to the child's question may discourage exploration. We should find the answer, it's not important to not know; finding a response with the help of each other can be very enjoyable.

5. One problem, several solutions: the discovery of various choices leads to creative thinking. One must know that one problem may have different solutions that might be all right.

6. Suggestions for different choices: Learning to recognize and choose is an important part of the creative process; let him to choose as possible. It is important for him to experience the outcome of his decisions and have a good sense of his choice. Example: When changing clothes, put three or four different shirts beforehand to choose one.

7. Listening carefully to the child indicates that your view is important to me: when we talk to him, we must listen with all senses from eyes to the face and body completely. When working we must ask him to wait until our work to be finished. Then he talks, when we listen to his words, we actually tell him that his thoughts are valuable to us, and this leads to new ideas. (Website).

\section{Conclusion}

One of the basic questions about creativity is whether it is possible to develop it? The result of study by Turence (1961) on a group of 6 to 8 year-old students shows that students who are accustomed to their own beliefs or methods get higher scores in creativity tests than in the control group. He concludes that children can be taught principles that improve the power of producing new ideas (Khanzadeh 1975: 54).

In general, the main elements of the philosophy of education that encourages creativity and innovation in students are:

1- Learning is a very important and entertaining issue.

2. Students are unique, respectable and affectionate.

3. Students must be active learners. They should be encouraged to bring their interests, experiences, thoughts and devices to classroom and allow them to discuss their daily work goals with coaches and to have autonomy.

4. Students should feel comfortable and encouraged without stress and pressure in the classroom. 
5. Students should have a sense of ownership and pride about their class; they should be involved in the class order and keeping it.

6. Students should have both power and responsibility in the classroom

Dr. Hamze Ganji and Dr. Hassan Pasha Sharifi, in a study, investigated the impact of brainstorming in increasing academic guidance of 40 male students and 40 female students (20 experimental and 20 control groups). After three months of holding the brainstorming sessions with different subjects in the experimental groups and analyzing the data using the covariance analysis, the results showed that the brainstorming method was effective in increasing the creativity of the male and female experimental groups.

These studies confirm the constructive knowledge and emphasize the need for active participation of learners in the learning process (Bard et al., 1991, Brophy, 1991, Caine, 1991, Newman, 1991, Provat, 1993, Rosinshilne and Myster, 1992).

Today, our community needs intelligent and creative people more than ever. For this reason, in the present situation, the issue of creativity is one of the most important issues in the field of school psychology.

\section{Practical suggestions}

Parents and instructors should be the creative model for children.

They should be aware of the nature and value of creativity and imagination.

They should value for the representations of the child as a unique and personal work.

They should plan for the environment.

They should make the imaginative environment of the child fertile to stimulate his creativity.

The atmosphere should be exciting and aesthetically pleasing.

They should communicate with others to make sure: At home and in the neighborhood, they encourage the creative and imaginative experiences of children.

They should provide access to artists, artisans, etc. in the school environment.

They should let them act freely.

They should teach children new and varied solutions.

They should respect the children's questions and guide them.

They should show to children that their beliefs are worthwhile.

They should ask questions about how and why.

They should encourage children and adolescents to guess.

They should avoid imposing a special pattern.

They should not excess in the acquisition of ready toys.

The last word is that today the education system as a social phenomenon is inseparable from social life and undertakes training skilled, compassionate, creative, and innovative people.

Creative and innovative managers and instructors can create valuable, questionable, creative and innovative children.

\section{References}

Amabil, Theresa (1996), "The Growth and Prosperity of Creativity in Children", translated by Hasan Ghasemzadeh, Tehran, the publication of Donyaye No.

Angeji, Leili, Turkman, Manouchehr (1999) "Children's Hand and Artistic Works", Fourth Edition, Tehran, Madrese Publishing. 
Baharestani, Maryam (2006), "Leisure, Mobility and Creativity", Peuvand Monthly, vol. 323, 322, 321.

Basis, Pierre and Jano, Hubert (2000) "What is Creativity" ?, Translated by Dr. Hossein Sarvari, Tehran, Publishing Abed

Bodo, Ellen (2006) "Creativity at the school", translation by Ali Khanzadeh, Chehr publishing.

Duffy, Bernadette (1958) "Promoting creativity and imagination in children", translated by Mahshid Yasai, Tehran, Ghoghnus Publishing.

F Sborn, Alex (1996) "Development of universal talent of invention and creativity", translated by Hasan Ghasemzadeh, Tehran, Nilufar publication.

Fathi, Heydar (2005) "The Influence of play and Toy on fostering Children's Mind and Creativity", Payvand Monthly, Nos. 309, 310,

Fathi, Heydar (2005) "The Influence of Play and Toy on fostering the Mind and Creativity of Children", Payvand Monthly, Tehran, no. 309, 310,11.

Ganji, Hamze and Sharifi, Hassan Pasha (2005) "The effect of brainstorming on increasing creativity of students", Quarterly Journal of Education No. 1.

Geminiyan, Vajiheh (2003) "The ways of cognition and prosperity of creativity in students", Pivand Monthly, No. 289

Imamgholi Wand, Fatemeh (2001) "Creativity and ways to increase it in students", Development of Educational Technology, Volume 7, Number 136

Khakpour, Negare (2006) "Play, an important part of the life of children", Peyvand Monthly Number 321,322, 323.

Mahjour, Siamak Reza (2001) "Play Psychology", Seventh Edition, Sasan Publishing

Motahari, Mohammad Reza (2002) "The causes of toy breaking by children", Peyvand monthly, No. 280.

Nasagizadeh, Ismail (2005) "Pathology of Creativity in children and Family ", Peyvand Monthly, No. 316

Petersen, Avalin (1999) "Methods of developing creativity in children", Translation by Behjat Najafi, Peyk Nobahar.

Salahshur, Mandana (2004) "Do you know how to train creative children?" Pyono Monthly, Nos. 1,3 .

Soleimani, Afshin (2003) "Barriers to Creativity in the Family and School Environment", Monthly Peyvand No. 284.

Turence, Pal (1979) "Creativity", translated by Dr. Hasan Ghasemzadeh, Tehran, publication of Donyaye Noor

http://www.workteams.unt.eda/literature/proceedikg/abstr 95: html pools paid. (2001)

http://www/gsm. corbelled/ASQ/asq.dec.abstnew.html.suttonrobert. et.al. (2001)

www.irarticles.com/articlecats/php. 